\title{
Qualified Coaches as a Requisite for Enhanced Sports Performance of Cross River State at National Sports Festival
}

\author{
P. E. Ekuri (Ph.D) \\ Department of Human Kinetics and Health Education \\ University of Calabar, Calabar
}

Received: July 7, 2017 Accepted: April 20, 2018 Online published: May 21, 2018

doi:10.5296/jpag.v8i2.13176 URL: https://doi.org/10.5296/jpag.v8i2.13176

\begin{abstract}
This study investigates qualified coaches as a requisite for enhanced sports performance of Cross River State at National sports festival. The study adopted the descriptive survey research design of Expost-facto type. The study population consists of 344 sports personnel in the six (6) local government headquarters hosting the six zonal sports offices of the state adopting the total enumeration technique. The questionnaire was the main instrument used to elicit information from 344 sports personnel, out of which 270 (78.5\%) copies of the questionnaire were duly completed and returned. The data collected were analyzed using frequency count, percentages and table with the aid of SPSS Version 21. The findings show that personnel have working experience, 65 accounting for $57 \%$ rated higher. Coaches had teacher's Grade II Certificate, while some on the whole had professional certificate 2 and few were graduates. The study also revealed that two sports which are judo and wrestling have 1 -2 coaches each while there are $3-4$ Coaches each in badminton, basketball, tennis, squash, swimming and volleyball. Athletics, handball, soccer, and table tennis have more than 4 coaches while boxing, cricket, cycling, hockey, marathon taekwondo and weight lifting had no coach at all. The coach should have Psychological and communicative knowledge and ability, as an analyzer, a coach needs the appropriate analytical tool together with theoretical and real-life pattern of interpretation in order to initiate a formulation of the problem that is appropriate to the client's particular issue and specify objective to bring about change. A coach should be able to reflect on both his analyses as well as his methods with regard to the underlying conception of humanity.
\end{abstract}

Keywords: Qualified coaches, sport performance, National sports, sports festival, Cross River State 


\section{Introduction}

The concept of coaching profession poses a special challenge. This is because a profession possesses certain characteristics that differentiate it from "occupations." When these characteristics do not apply in full or are absent, it is referred to as "semi-profession" (Kuhl, 2006). Moreso, many definitions have been attached to the concept while some are broad some are narrow: e. g. a broad definition of profession thus: an individual pursuit of professionalism; Voluntary commitment; and non-binding common sense standards.

The narrow definition of profession runs as standards for ethics, qualifications, dialogical attitudes, application of concepts and methods, quality assurance; theoretical and methodological plurality; Multi-perceptivity in concepts and in their application; Relevant spectrum of competencies and experience. Up till now, developments in coaching appear to correspond mainly to the broad definition. From a long-term perspective, we deem it necessary to promote professional education in line with the narrow definition and in doing so achieve consolidation. Otherwise, there is the danger that coaching as a type of counseling will not be able to establish itself on the market after a rapid growth period and thereby lose its significance equally quickly.

However, as a result of criticisms, an expert committee in Germany decided to adopt the term "profession" in the manner it is referred to in discussions in sociological literature on professions (Schmidt-Lellek, 2006, Kühl, 2006, Schmid, 2003). The international Coach Federation (2011) prescribes a professional conduct to cover boundaries of competence; training; continuous professional development; and commitment to a code of Ethics.

Coaching is an interactive process that helps individuals and organizations to develop more rapidly and produce more satisfying results. Coaches work with clients in all areas including business, career, finances, health, sports and relationships. As a result of coaching, clients set better goals, take more action, make better decisions, and more fully use their natural strengths.

Professional coaches are trained to listen and observe, to customize their approach to the individual client's needs, and to elicit solutions and strategies from the client. They believe that client is naturally creative and resourceful and that the coach's job is to provide support to enhance the skills, resources, and creativity that the client already has. While the coach provides feedback and an objective perspective, the client is responsible for taking the steps to produce the results he or she desires. Coaching does not focus directly on relieving psychological pain or treating cognitive or emotional disorders.

However, in respect of consulting, coaches are experts in the coaching process and may not have specific knowledge of a given subject area or industry. Where coaches have expertise in other areas, they may use it to facilitate the coaching process. Coaches do not use this particular expertise to diagnose, direct, or design solutions for the client. Relationship is the foundation of coaching. In coaching, information drawn from the client is used by the coach to promote the client's awareness and choice of action. Coaching has the freedom and flexibility to address a wide variety of personal and professional topics. Coaching is not 
necessarily restricted to a narrowly defined issue nor its scope determined in any other way.

In coaching any contribution, the coach makes to producing client's desired outcome is through on-going interaction with the client. Coaching is designed to provide clients with a greater capacity to produce results and a greater confidence in their ability to do so. It is intended that client do not leave coaching with a perception that they need to rely on a coach in order to produce similar results in the future.

Sports coaching seem to fall under the consulting category where coaches are experts and must have knowledge about the specific sport they are coaching. Hence, it makes them authoritative. Thus a professional coach can be described as an expert in establishing a relationship with people in a series of conversations with the purpose of serving the clients to improve their performance or enhance their personal development or both, choosing their own goals and ways of doing it (European Mentoring \& Coaching Council, 2011).

According to International Coach Federation (2011), "Coaching is facilitating the client's learning process by using professional methods and techniques to help the client to improve what is obstructive and nurture what is effective in order to reach the client's goals."

Coaching can also be described as partnering with clients in a thought-provoking and creative process that inspires them to maximize their personal and professional potential (Association of Coaching, 2012). Within organizational contexts coaching may include 'one-to-one' or 'one-to-several' interactions.

In National Sports Festivals and other national competitions all states are supposed to present participants in all approved sports. The success of these state in such competitions depends on how well trained these teams are in their specialized sports. Adequate preparation of teams will increase the chances of winning maximum number of medals in the accepted categories of sports.

Granting that all states appreciate the participation in festivals in particular and sports in general, for the fact that it contributes meaningfully to the development of unity, some social traits and of equal importance, health of the participants which is effect will contribute to the productivity of the participants. It then follows that all the states should be able to put equal or about the same effort to participating and competing effectively in order to achieve the stated objectives (Ufot, 1984). But this has not been the case with Cross River State. Right from the inception of National Sports Festival. It is evident that the performance of Cross River State has been progressively poor over the years.

\section{Statement of the Problem}

Overtime, it has been observed that there is low sports performance of Cross River state at the National sport festival. This is due largely to several complaints among the sports personnel and athletes about their kind of treatment mated out to them. This has significantly reduced their performance level due to poor motivational strategies such as money, scholarship, appointment opportunities, to travel abroad, hardly sent for regular courses; allowances not paid regularly, incentives are not given for outstanding performance. The role 
of the qualified coaches to meet the demand of sports personnel and athletes and to efficiently perform their duty cannot be overemphasized as this will efficiently enhanced sports performance of the Cross River state at the National sports festival.

\section{Research Questions}

To carry out this research, the following research questions were posed to guide the study.

1. What is the experience of personnel (Coaches/organizers) of Cross River state in enhancing sports performance at National sports festival?

2. What is the qualification of personnel (Coaches/organizers) of Cross River state in enhancing sports performance at National sports festival?

3. What are the opinions of the personnel on the number of coaches per sport?

4. What are the opinions of the athletes on the number of coaches per sport?

\section{Literature Review}

One of the major problems militating against effective performance is lack of qualified human resources. Human resources are concerned with all individual that are needed to make sorts programme a success. Examples of these personnel includes: coaches, trainers, organizers, administrators, exercise physiologist, sports personnel are those who handle or judge the participants with the law of the game of the sports being organized.

Umoh (2005) opined that qualified sports personnel are the one who has undergone a programme of a planned instruction in Physical Education. In the same vein, Asua (2006) found out that sports masters, coaches, games official; or match officials, referees, umpires, judges, arbiters have important influence on athletes' performance in sports. They control the athletes and officiate matches or contests and enforce the laws on them. He said, the caliber and strength of personnel are very important in sports.

Amuchie (2006) supported the above assertion by adding that other qualities include willingness to accept responsibility and understanding of the work, command of administrative technique and good intellectual capacity. Also that another essential requirement for the successful implementation of sports development programmes is to provide adequate trained and experienced manpower, equipped with necessary skills.

Morakinyo and Aluko (2008) asserted that sport is a technical area that requires adequate preparation for those that will manage sports. A good sports manager or administrator should have a thorough knowledge of sport, possess educational degree preferably in the area of sport administration, professional attitude and commitment in addition to individual features like intellect, justice, flexibility, honesty, sincerity, leadership and genuine interest in the management of sports.

They lamented on the caliber of people managing sports in Nigeria, they observed that there is nothing fundamentally wrong with Nigeria or her athletes the problem is that we have 
sports administrators who are not professionally prepared for the job at the hums of affairs.

In confirmation of the above observation, Daniel (2005), stated that because of the emphasis on winning in sports competitions most of the coaches and sports masters who are ill-trained and un-professional themselves bring in ill-prepared and ill-equipped competitors who cheat by bringing down their ages in order to win medals. Daniel said such sharp practices by these ill trained masters and/or unprofessional coaches deprive the true eligible athletes of their chances to compete in their respective categories.

Daniel (2005) further remarked that, the right attitude towards sports is not developed in athletes, they are no longer taught that success in sports is a result of hard practices (training) and learning of skills and that there is no short cut to winning, instead, every athletes is attempting to win at all cost. Ozualor and Okafor (2001) emphasized that qualified coaches or sport personnel is an indispensable factor in the administration of all physical education and sports programme and are in-charge of handling facilities, equipment, staff supervision and organization set up in Nigeria. They furthered said that where there is no qualified and trained coach, a staff who has interest in sport is capable to handle sports programme can act pending when experts can be employed.

In line with what the above opinion reflected, Ikulayo (2008) also confirmed and pointed out that it is not enough to be able to plan, but to be a competent, dedicated and qualified personnel is a requirement in executing the programme. She went ahead to say that people employed for sports must have been exposed to adequate knowledge and understanding of sports management, administration, coaching, psychology, sociology, welfare and sport science.

National Association for Sports and Physical Education (NASPE) of America (1979) in recognition of the need and importance of qualified and certified personnel in the teaching of physical education came up with an official statement which was adopted on March $19^{\text {th }}$, 1979. It said that only certified personnel should be used in the teaching of physical education. It arrived at its stand from two considerations.

1. The pedagogy and

2. Legal considerations

Under pedagogy, it agreed that apart from teaching the development of psychomotor skills, and physical fitness, physical education seeks to instruct in the cognitive and affective domains, with special attention to the concomitant learning in the physical education experiences. This aspect, the body said, has been considered the highest state of the physical education experiences and as such expert's instruction is enhanced when the assigned teacher is certified as opposed to the use of non-certified. From legal consideration, the association noted that students do become injured while participating in basic instruction programmes. Frequently, these injuries are as a result of an accident and too often these have been injuries which could have been avoided if certified teachers/coaches were used. These two aspects are very glaring both in the light of performance and safety of athletes in sports. 


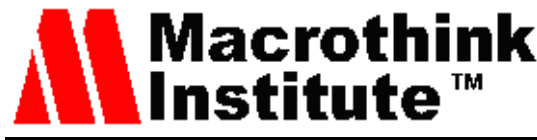

The coach needs to understand how a youth functions at his particular level of development with full appreciation of skeletal growth, muscular development and physical and emotional limitations. The third is an understanding of the game he coaches. Thorough Knowledge of techniques, rules and regulations, and similar information is basic. The fourth qualification is having a desirable personality and character. Patience, understanding, kindness, honesty, sportsmanship, sense of right and wrong, courage, cheerfulness, affection, humor, energy, and enthusiasm are imperative, since the youths will be idolizing and emulating his every move.

Yet sadly, too often coaches are chosen because of only one qualification that they have played the game. This is a very wrong impression and that the reason for our failure of especially indigenous coaches for the job of coaching the super Eagles where Nigerians play their politics in appointments. It is therefore, important to employ a coach who has fully trained in his claimed field of specialization.

\section{Methodology}

The study adopted descriptive survey research which includes the Causal-comparative (Ex-post-Facto) method type. The targeted population of this study consists of 344 sports personnel in the six (6) local government headquarters hosting the six zonal sports offices of the state. A total of 344 questionnaires were administered, 270 were retrieved which is $(78.5 \%)$ of the total population of sports personnel using total enumeration technique. A questionnaire was the instrument for data collection, it consisted questions on experience and qualification of personnel (Coaches/organizers) and source for their opinion on the number of coaches per sport in the six (6) local government headquarters hosting the six zonal sports offices of the state. The questionnaire was pre-tested using 30 personnel in Oyo State Sports Council in Ibadan Metropolis. The reliability of the questionnaire was assessed using the Cronbach Coefficient Alpha method. The reliability for the whole questionnaire was 0.86 alpha levels. Data collected were subjected to various statistical analyses using SPSS version 21. Descriptive statistics such as simple percentages, frequency and tables were used in analyzing data.

\section{Results and Discussions}

Table 1. Experience of personnel (years)

No $=114$

\begin{tabular}{|c|c|c|c|c|c|c|c|c|}
\hline & \multicolumn{2}{|c|}{$4-5$} & \multicolumn{2}{|c|}{$6-10$} & \multicolumn{2}{|c|}{$11-15$} & \multicolumn{2}{|c|}{16 and } \\
\hline & No & $\%$ & No & $\%$ & No & $\%$ & No & $\%$ \\
\hline Coaches & 30 & 57.6 & 9 & 17.3 & 8 & 15.3 & 5 & 9.6 \\
\hline Organizers & 20 & 51.2 & 5 & 12.8 & 8 & 20.5 & 6 & 20.0 \\
\hline Others & 15 & 65.2 & 4 & 17.3 & 4 & 17.3 & - & - \\
\hline Total & 65 & 57.0 & 18 & 15.8 & 20 & 17.5 & 11 & 9.6 \\
\hline
\end{tabular}

Research Question 1: What is the experience of personnel (Coaches/organizers) of Cross River state in enhancing sports performance at National sports festival?

On experience of personnel, 65 accounting for $57 \%$ have working experience between $1-5$ 
years, 18 of them that is $15.8 \%$ have from 6 - 10 years' experience while 20 respondents (17.5\%) fall within $11-15$ years. Only 11 respondents representing $9.6 \%$ have an experience spanning over 15 years. This commensurate with the study of Umoh (2005) who opined that qualified sports personnel are the one who has undergone a programme of a planned instruction in Physical Education. In the same vein, Asua (2006) found out that sports masters, coaches, games official; or match officials, referees, umpires, judges, arbiters have important influence on athletes' performance in sports. They control the athletes and officiate matches or contests and enforce the laws on them. He said, the caliber and strength of personnel are very important in sports.

Table 2. Qualification of personnel

No $=114$

\begin{tabular}{|c|c|c|c|c|c|c|c|c|c|c|}
\hline & \multicolumn{2}{|c|}{ TC II } & \multicolumn{2}{|c|}{ WASC } & \multicolumn{2}{|c|}{$\begin{array}{l}\text { Professional/ } \\
\text { Organization } \\
\text { certification }\end{array}$} & \multicolumn{2}{|c|}{$\begin{array}{c}1^{\text {st }} \\
\text { Degree }\end{array}$} & \multicolumn{2}{|c|}{$\begin{array}{c}\text { Post } \\
\text { Graduate }\end{array}$} \\
\hline & No & $\%$ & No & $\%$ & No & $\%$ & No & $\%$ & No & $\%$ \\
\hline Coaches & 25 & 48.1 & 12 & 23.1 & 13 & 25 & 2 & 3.8 & - & - \\
\hline Organizers & 18 & 46.1 & 13 & 33.3 & 7 & 17.9 & 1 & 2.5 & - & - \\
\hline Others & - & - & 12 & 52.1 & 3 & 13.0 & 8 & 34.7 & - & - \\
\hline Total & 43 & 37.7 & 37 & 32.5 & 23 & 20.2 & 11 & 9.6 & - & - \\
\hline
\end{tabular}

Research Question 2: What is the qualification of personnel (Coaches/organizers) of Cross River state in enhancing sports performance at National sports festival?

In table 2, out of a total of 114 respondents, 25 out of 52(48.1) coaches had teacher's Grade II Certificate, only 23 respondents on the whole had professional certificate 2 and equivalent of $3.8 \%$ were graduates. None of the 114 respondents have beyond the first degree. This agreed with the study of Amuchie (2006) who supported the above assertion by adding that other qualities include willingness to accept responsibility and understanding of the work, command of administrative technique and good intellectual capacity. Also that another essential requirement for the successful implementation of sports development programmes is to provide adequate trained and experienced manpower, equipped with necessary skills.

According to Morakinyo and Aluko (2008), sport is a technical area that requires adequate preparation for those that will manage sports. A good sports manager or administrator should have a thorough knowledge of sport, possess educational degree preferably in the area of sport administration, professional attitude and commitment in addition to individual features like intellect, justice, flexibility, honesty, sincerity, leadership and genuine interest in the management of sports. 


\section{Macrothink}

Table 3. Personnel opinion on the number of coaches per sport

No $=114$

\begin{tabular}{lcccc}
\hline & $\mathbf{1 - 2}$ & $\mathbf{3 - 4}$ & $\mathbf{5}$ and above & None \\
\hline Athletes & & $\checkmark$ & $\checkmark$ & \\
Badminton & & $\checkmark$ & & \\
Basketball & & & $\checkmark$ \\
Boxing & & $\checkmark$ & $\checkmark$ \\
Cricket & & & \\
Cycling & & & \\
Handball & & & $\checkmark$ \\
Hockey & $\checkmark$ & & \\
Judo & & $\checkmark$ & \\
Tennis & & $\checkmark$ & $\checkmark$ & \\
Marathon & & $\checkmark$ & \\
Squash & & & \\
Soccer & & & \\
Swimming & & $\checkmark$ & \\
Table tennis & & & \\
Taekwondo & & $\checkmark$ & \\
Volleyball & & & \\
Weight lifting & $\checkmark$ & & \\
Wrestling & $\checkmark$ & & \\
\hline
\end{tabular}

Research Question 3: What are the opinions of the personnel on the number of coaches per sport?

Table 4. Athletes opinion on the number of coaches per sport

No $=156$

\begin{tabular}{lcccc}
\hline & $\mathbf{1 - 2}$ & $\mathbf{3 - 4}$ & $\mathbf{5}$ and above & None \\
\hline Athletes & & $\checkmark$ & $\checkmark$ & \\
Badminton & & $\checkmark$ & & $\checkmark$ \\
Basketball & & & $\checkmark$ \\
Boxing & & & \\
Cricket & & & \\
Cycling & & & \\
Handball & & & $\checkmark$ \\
Hockey & $\checkmark$ & & \\
Judo & & & \\
Tennis & & $\checkmark$ & \\
Marathon & & $\checkmark$ & \\
Squash & & & \\
Soccer & & & \\
Swimming & & $\checkmark$ & & \\
Table tennis & & & \\
Taekwondo & & $\checkmark$ & \\
Volleyball & & & \\
Weight lifting & $\checkmark$ & & \\
Wrestling & $\checkmark$ & & \\
\hline
\end{tabular}

Research Question 4: What are the opinions of the athlete's on the number of coaches per sport?

Table 3 and 4 present personnel and athletes' opinions on the number of Coaches per sport. According to these tables, two sports which are judo and wrestling have $1-2$ coaches each 
while there are $3-4$ Coaches each in badminton, basketball, tennis, squash, swimming and volleyball. Athletics, handball, soccer, and table tennis have more than 4 coaches while boxing, cricket, cycling, hockey, marathon taekwondo and weight lifting had no coach at all. This agreed with the study of Ozualor and Okafor (2001) who emphasized that qualified coaches or sport personnel is an indispensable factor in the administration of all physical education and sports programme and are in-charge of handling facilities, equipments, staff supervision and organization set up in Nigeria. They furthered said that where there is no qualified and trained coach, a staff who has interest in sport is capable to handle sports programme can act pending when experts can be employed. In line with what the above opinion reflected, Ikulayo (2008) also confirmed and pointed out that it is not enough to be able to plan, but to be a competent, dedicated and qualified personnel is a requirement in executing the programme. She went ahead to say that people employed for sports must have been exposed to adequate knowledge and understanding of sports management, administration, coaching, psychology, sociology, welfare and sport science.

\section{Conclusion and Recommendations}

To conceptualize coaching as a profession represents a special challenge. (Schmidt-Lellek, 2012). The traditional concept of profession however, must indeed be taken into consideration, but also amended to satisfy current social conditions and specific sphere of activity that is coaching. In addition to the professional development of coaching, the professionalism of the coach is an essential measure of the quality of coaching that it should substantiate an secure not only the technical competence of the coach, but also the independence of his occupational reasoning and conduct. The coach should have a sound psychological and economic contextual knowledge in order to understand what the issue is on the intrapersonal, interpersonal and corporate levels, the coach should have Psychological and communicative knowledge and ability, as an analyzer, a coach needs the appropriate analytical tool together with theoretical and real-life pattern of interpretation in order to initiate a formulation of the problem that is appropriate to the client's particular issue and specify objective to bring about change. More so, a coach should be able to reflect on both his analyses as well as his methods with regard to the underlying conception of humanity.

\section{References}

Amuchie, F. A. (2006). Problems of administration and organization of intramural, recreational sports programmes in Nigeria Universities. Research report, University of Nigeria Nsukka, Enugu State.

Asua, A. J. (2006). Organization of sports meet in secondary schools. A paper presented at State wide NAPHER Seminar, Uyo, Akwa Ibom State.

Daniel, A. I. (2005). Problems of sports development in Nigeria. Report of the National Committee on problems of sports development in Nigeria.

Ikulayo, P. B. (2008). Exploring multifaceted dimension in exercise and sports psychology. Ibadan, Nigeria: Olu Akin Publishers. 


\section{Mll Macrothink}

Journal of Public Administration and Governance ISSN 2161-7104 2018, Vol. 8, No. 2

Kuhl, S. (2006). Coaching zwischen Qualitats problemen und professionalisierungsbemuhungen. Thesen zur Entwicklung des coaching (coaching between quality problems and efforts towards Professionalization. Theses on the development of coaching) organizations Berating, supervision, coaching.

Morakinyo, Y. E. O., \& Aluko, E. O. (2008). Management factors a predictor of sport development in selected sports. Federation of the Federal Ministry of Sports and Social Development. International Journal of African and African American Studies, 11(1).

Ozualor, C. G., \& Okafor, R. U. (2001). Physical education for junior secondary schools, Onitsha Etukom.

Schmid, B. (2003). Systemische Professionalitat. Und Transaktionsanalyse. Bergisch Gladbach: EHP.

Schimidt, L. C. J. (2006). Anmerkugen zur professionalisierung des coaching cuf dem hintergrund des Klassischen professionsbegriffs. Organizationberatung, Super-vision, coaching. https://doi.org/10.1007/s11613-006-0025-1

Schmidt, L. C. J. (2012). In Deutscher Bundesverband Coaching e.V'. (DBVC) German Federal Association for Executive Coaching). Guidelines and Recommendations on the Development of Coaching as a Profession. Retrieved in October, 2016 from www.dbvc.de.

Umoh, L. E. (2005). The role of sports and recreation in combating adolescence delinquency in secondary schools. Onitsha: Hybrid Publishers.

\section{Copyright Disclaimer}

Copyright for this article is retained by the author(s), with first publication rights granted to the journal.

This is an open-access article distributed under the terms and conditions of the Creative Commons Attribution license (http://creativecommons.org/licenses/by/4.0/). 